\title{
YERBILIMLERI
}

Bulletin for Earth Sciences

Yerbilimleri, 2019, 40 (3), 326-351, DOI: 10.17824/yerbilimleri.664918

Hacettepe Üniversitesi Yerbilimleri Uygulama ve Araştırma Merkezi Bülteni

Bulletin of the Earth Sciences Application and Research Centre of Hacettepe University

\section{Sismotektoniğe ve sismik boşluğa DInSAR yaklaşımı: Kuzey Anadolu Fay Zonunun Erzincan havzası kesimi (doğu Türkiye)}

DInSAR approach to seismotectonics and seismic gap: Erzincan basin section of the North Anatolian Fault Zone (eastern Turkey)

\author{
ONUR KÖSE ${ }^{*}$, MEHMET TEKIN YÜRÜR ${ }^{2}$, JEAN CHOROWICZ ${ }^{3}$ \\ 1 Van Yüzüncü Yıl Üniversitesi, Mühendislik Fakültesi, Jeoloji Mühendisliği Bölümü, Kampüs, Tuşba 65040 Van \\ 2 Hacettepe Üniversitesi, Mühendislik Fakültesi, Jeoloji Mühendisliği Bölümü, 06800, Beytepe, Ankara \\ 3 Sorbonne Universités, Université Pierre et Marie Curie (Paris VI), Institut des sciences de la Terre de Paris (ISTeP) - UMR \\ 7193 Tectonics, 4 place Jussieu 75005 Paris FRANCE
}

Geliş (received): 25 Aralık (December) 2019

Kabul (accepted) : 28 Aralık (December) 2019

ÖZ

InSAR (İnterferometrik Sentez Açılımlı Radar) ve GNSS (Küresel Navigasyon Uydu Sistemi) gibi uzay jeodezisi tekniklerinin sağladığı verilerle üst kabuk ve litosferin diğer katmanlarının fiziksel özellikleri ve reolojisine yönelik çok sayıda model geliştirilmiştir. Bu modeller yine deprem tahminlerine yaklaşımda bulunmak üzere intersismik döneme yönelik InSAR çalışmalarında kullanılmaktadır. Ancak herhangi bir fay segmentinde gerilimleri boşaltan büyük depremler, birkaç yüz ile birkaç bin yıllık bir süre aralığında meydana gelirken, genellikle en çok on yıllık bir zaman aralığını kapsayan deformasyon gözlemleri tam bir deprem çevriminde oldukça küçük bir zaman aralığını temsil ederler. Bu kısa süreli deformasyon gözlemlerini sismik tehlikede kullanmak için, fay zonlarının uzayda ve zamanda nasıl deforme olduğuna dair daha iyi modellere intiyaç duyulur. Dolayısıyla, tektonik havzalar ve fay zonlarındaki ana segmentler ile diğer yapısal unsurlar etrafındaki deformasyonlara odaklanan ve aynı zamanda gözlemlenen deformasyonlar ile bu yapısal unsurların arasındaki ilişkiyi de ele alan InSAR çalışmaları, deprem tahminleri açısından oldukça önem arz edebilir. Bu bağlamda makalemizde, Kuzey Anadolu Fayı (KAF) üzerinde bulunan Erzincan havzasının tektonik özelliklerini,

https://doi.org/10.17824/yerbilimleri.664918

Onur KÖSE onurkose@yyu.edu.tr

1 Van Yüzüncü Yıl Üniv. Müh. Fak., Jeoloji Müh.Böl. Kampüs, Tuşba 65040 Van ORCID 0000-0003-3470-7488

2 Hacettepe Üniv. Müh. Fak., Jeoloji Müh. Böl, 06800, Beytepe, Ankara ORCID 0000-0002-3077-8249

3 Sorbonne Univ. UPMC (Paris VI), Institut des sciences de la Terre (ISTeP) - UMR 71934 place Jussieu 75005 Paris FRANCE 
InSAR ile belirlenmiş deformasyon alanları ile birlikte ele alarak değerlendirmeyi düşündük. Buna yönelik olarak, InSAR tekniğinin çok büyük alanları ve yüzlerce interferogram analizini kapsayan modern kullanımı yerine, havza içine odaklanmış az sayıda interferogramla belirlenen deformasyon alanlarının yapısal jeoloji açısından değerlendirildiği başlangıçtaki eski usül kullanımını tercih ettik.

Erzincan tektonik çökme havzasında son yüzyılda iki yıkıcı deprem meydana gelmiştir (1939, M: 7.8 - 8.2 ve 1992, M:6.8). Önceki çalışmalar, havzanın KAF zonu boyunca çek-ayır tipinde bir açılmanın sonucu olarak oluştuğunu göstermektedir. Ovacık fayı (OF) aktivitesi havzayı genişletmektedir. Havzanın doğusunda KAF boyunca en az 75 km uzanan bir sismik boşluk zonu bulunmaktadır. Bu sismik boşluk hattının, batıda yaklaşık 22 km uzunluğundaki Sansa ve doğuda yaklaşık 53 km uzunluğundaki Yedisu olmak üzere, iki ana segmentten meydana geldiği düşünülmektedir.

Çalışmamızda, 13 Mart 1992 tarihindeki Erzincan depremi ( $\mathrm{M}=6.8$ ) sonrasındaki yaklaşık 2.5 yıllık postsismik bir dönem (1993-1995) için, ERS-1 uydusunun SAR verilerinden Farksal İnterferometrik SAR (DInSAR) tekniği ile üretilen bir interferogramda belirlenen deformasyon alanlarını, havzanın yapısal jeoloji unsurlarıyla karşılaştırdık. İnterferometrik deformasyon bulguları Erzincan ovasının kenarlarına yakın tektonik hatlar üzerinde belirginleşmişlerdir. Dikey yön bileşenlerinde çökmeye karşılık gelen yerdeğiştirme miktarları, havzanın kuzey kenarı çevresinde, güney kenarındakilerden daha yüksektir. Havzanın kuzey kenarı ve KAF zonu boyunca, Erzincan kent merkezinin kuzeybatısı ve kuzeyinde gelişen deformasyonlar, doğusu ve kuzeydoğusunda gelişen deformasyonlara göreceyle daha düşük hız ve seviyelerdedir. Bu, her iki alanın birlikte çökerlerken, göreceyle daha yavaş çöken kuzeybatı kesiminde transpresif zonların ve push-up yapılarının gelişmesine ışık tutmaktadır. İnterferogramda, Erzincan ovasının yaklaşık doğu çıkışından itibaren deformasyon gelişimi gözlenmemektedir. Bu nedenle havzanın doğusuna doğru ilerlerken sismik boşluk zonuna yaklaştıkça, KAF segmentinin daha düşük kayma miktarlarına sahip olan bir davranış sergilediği düşünülmüştür.

Çalışmamızda ayrıca, 1939 Erzincan depreminin (M: 8.0) Ekşisu (Erzincan) - Bahçe Köyü (Koyulhisar, Sivas) arasında 185 km uzunluğundaki yüzey kırığı haritalamasını içeren, oldukça zor şartlar altında üretilmiş hayranlık ve saygı uyandıran bilim-antik özellikteki eski bir saha raporuna (Stchepinsky vd., 1940) kısaca yer verilmiştir.

Anahtar Kelimeler: Aktif tektonik, radar, SAR, interferometri, InSAR, deprem tahmini. 


\section{ABSTRACT}

With the help of space geodesy techniques such as InSAR (Interferometric synthetic aperture radar) and GNSS (Global navigation satellite system), a number of models have been developed for the physical properties and rheology of upper crust and other layers of the lithosphere. These models are also used in InSAR studies for interseismic period in order to approach earthquake predictions. However, large earthquakes that release total strains in any fault segment occur over a period of several hundred to several thousand years, while deformation observations, which usually span a maximum period about ten years, represent a very small time interval in a complete earthquake cycle. To use these short-term deformation observations in seismic hazards, better models of how the fault zones deform in space and time are needed. Consequently, InSAR studies focusing on the deformations around the main segments and other structural elements in the tectonic basins and fault zones, also addressing the relationship between the observed deformations and the behavior of these structural elements, may be very important in terms of earthquake predictions. In this respect, we aimed in our paper to associate the tectonic characteristics of the Erzincan basin, a part of the North Anatolian Fault (NAF) zone, with the deformation clusters determined by the InSAR technique. To do this, instead of modern usage of InSAR technique in which hundreds of interferograms are calculated, we preferred its old-school usage which allows us to evaluate deformation areas in terms of structural geology by a few interferograms focused into the basin.

In the last century, two destructive earthquakes happened in the Erzincan tectonic subsidence basin (1939, M: 7.8 - 8.2 and 1992, M:6.8). Previous studies suggest that the basin forms as a result of pullapart type opening along the NAF zone. The Ovacık Fault (OF) activity widens the basin. In the east of the basin, there is a seismic gap zone extending for at least $75 \mathrm{~km}$ along the NAF. This seismic gap is thought to be made up of two main segments which are the nearly $22 \mathrm{~km}$ long Sansa in the west and the $53 \mathrm{~km}$ long Yedisu in the east.

In our study we compared the deformation areas, observed on the interferogram generated by Differential SAR interferometry (DInSAR) technique from the ERS-1 satellite SAR data, acquired in the postseismic period of 2.5 years between 1993-1995 following the March 131992 earthquake in Erzincan (M: 6.8), with the structural aspects of the basin. Interferometric deformation findings were observed on tectonic zones near the boundaries of Erzincan plain. The amounts of displacements corresponding subsidence in vertical components of direction are higher around the northern boundary of the basin than those on the southern boundary. Along the northern boundary of the basin and the NAF zone, the deformations that occur in the northwest and north of Erzincan city have lower slip rates relative to deformations in the east and northeast. This sheds light on the development of 
transpressive zones and push-up structures in the relatively slower northwestern part while both areas collapse together. On the interferogram, deformation clusters are not observed in the eastern part of the Erzincan basin. Therefore, as it approaches the seismic gap zone towards the east of the basin, the NAF segment is thought to exhibit a behavior with lower slip rates.

We have also shortly mentioned a quaint and venerable, a so said science-antique, field report (Stchepinsky et al., 1940) established under very harsh conditions that comprises $185 \mathrm{~km}$ long surface rupture mapping of the 1939 Erzincan earthquake (M: 8.0) between Ekşisu (Erzincan) and Bahçe village (Koyulhisar, Sivas).

Keywords: Active tectonics, radar, SAR, interferometry, InSAR, earthquake prediction.

\section{Giriş}

Bir depremin sergilediği yüzey deformasyonları ilk kez ABD'nin batısındaki Landers depremi (M = 7.3) için, Massonnet vd. (1993) tarafından, ERS-1 uydusu verileri kullanılarak radar interferometrisi tekniğiyle haritalanmıştır.

Bir uzay jeodezisi yöntemi olan İnterferometrik Sentez Açılımlı Radar (InSAR) tekniği başlangıçta, genellikle kısıtlı boyutlardaki alanlara yönelik olarak sayılı interferogramların üretilebildiği çalışmalar için, NASA ve CNES gibi belirli kuruluşlara bağlı özel amaçlı laboratuvarlarda dönemin en hızlı bilgisayarları olan iş istasyonları üzerinde hayata geçirilmiştir. Çeşitli jeolojik aktivitelere bağlı olarak yer yüzeyinde gelişen deformasyonlarının belirlenmesi ve buna yönelik kantitatif değerlendirmeler için kullanılan InSAR tekniğinin kullanımı, günümüzde oldukça yaygınlaşmıştır. Dizüstü ve kişisel bilgisayarların iş yapma kapasitelerinin ve hızlarının çok yüksek seviyelere taşınmış olması, günümüzde tekniğin daha çok sayıda araştırmacı tarafından kullanılmasında ve geliştirilmesinde önemli bir rol oynamaktadır. Bu metodolojinin fiziği ve ana uygulamaları birçok makalede ele alınmıştır (örneğin, Zebker ve Goldstein, 1986; Goldstein vd., 1993; Massonnet ve Rabaute, 1993; Rossi, 1996; Hansen, 2001).

Tekniğin erken evre çalışmaları az sayıda interferogram üretilmesini esas alıyorken, dünyanın çeşitli bölgelerinde intersismik dönemlere ilişkin InSAR çalışmaları artık, genellikle yüzlerce kilometre uzunluğundaki binili komşu yörünge şerit görüntülerinin bölgesel boyutta entegre edilerek büyük bütünler halinde işlenebildiği (örneğin, Jolivet vd., 2012; Wang ve Wright, 2012; Kaneko vd., 2013; Tong vd., 2013; Cavalié ve Jónsson, 2014) yüzlerce interferogram analizini kapsamaktadır (Walters vd., 2014). 
Üst kabuk ve diğer litosferik katmanların elastik ve/veya viskoelastik davranışlarını esas alarak fiziksel özelliklerine, reolojisine ve deformasyonlarına ilişkin,1970'li yıllardan günümüze kadar yapılan çok sayıdaki model (örneğin, Savage ve Burford, 1973; Savage ve Prescott 1978; Prescott ve Nur, 1981; Thatcher, 1983; Savage, 2000; Johnson vd., 2007; Hearn vd. 2009; Lapusta ve Liu, 2009; Barbot vd., 2012; Christopher vd., 2012; Yamasaki ve Houseman, 2012) ile bunları geliştirmeye yönelik benzer araştırmalara (örneğin, Scholz, 1988; Marone, 1998; Hearn vd., 2002; Pollitz, 2005; Hetland ve Hager, 2006; Vaghri ve Hearn, 2012), GPS (Küresel Konuşlandırma Sistemi), GNSS (Küresel Navigasyon Uydu Sistemi) ve InSAR gibi uzay jeodezisi tekniklerinin verileriyle yapılan çalışmalar (örneğin, Peltzer vd., 1996; Kenner ve Segall, 2000; Bürgmann vd., 2002; Ergintav vd., 2009) büyük katkılar sağlamıştır. Bu modeller, fay zonları üzerinde ve çevresinde deprem eşlikli (kosismik), depremler arası (intersismik) ve deprem sonrası (postsismik) dönemlere ilişkin yatayda ve düşeyde meydana gelen kabuk davranışlarına, zaman içerisindeki yerdeğiştirme miktarları ve hızlarına yönelik çok sayıda çalışmaya temel oluşturmaktadır. Fay zonlarındaki intersismik dönem deformasyonların bu modeller aracılıyla InSAR tekniğinde değerlendirmeye alınmasının, depremlerin öngörülmesi çalışmalarına önemli bir ivme ve katkı sağlayacağı düşünülmektedir.

Bununla birlikte, herhangi bir fay segmentinde ana-şok depremler tipik olarak birkaç yüz yıldan birkaç bin yıla uzanabilen bir süre aralığında meydana gelir ve deformasyon gözlemleri genellikle sadece bir on yıl veya daha kısa süreli zaman periyotlarını kapsar (Wright, 2016). Bu nedenle, modern cihazlarla tek bir fay segmenti için tam bir deprem döngüsünü kapsayan deformasyon gözlemleri yapılmamaktadır (Meade vd., 2013; Hussain, 2016). Mevcut modellerin çoğunu ayırt edebilmek için, intersismik dönemde farklı zamanlarda yapılacak daha çok sayıda yüzey deformasyonu gözlemleri yapılması gerekir (Hussain, 2016). Bu kısa süreli deformasyon gözlemlerini sismik riskte kullanmak için fay zonlarının uzayda ve zamanda nasıl deforme olduğuna dair daha iyi modellere intiyaç duyulmaktadır (Wright, 2016). Dolayısıyla, fay zorlarındaki ana segmentler ile tektonik havzalardaki yapısal unsurlar çevresinde gelişen deformasyonlara odaklanan ve belirlenen deformasyonların bu yapısal unsurların davranışlarıyla ilişkilendirilmesini ele alan çalışmalar ayrıca bir önem arz edebilir.

Bu bağlamda makale çalışmamızda, Kuzey Anadolu Fayı (KAF) üzerinde bulunan Erzincan havzasının (Şekil 1) tektonik unsurlarının aktivitelerini, InSAR ile belirlenmiş deformasyon alanları ile birlikte ele alarak değerlendirmeyi düşündük. Bu çalışmada havzanın yapısal jeolojisi ile yerdeğiştirme ortamlarına ilişkin deformasyon verilerinin morfo-tektonik olarak karşılaştırılması hedeflenmiştir. Buna yönelik olarak, InSAR tekniğinin yüzlerce km genişlikte alanların hareket hızı dağııımlarını yansıtan modern kullanımı yerine, havza içine odaklanmış az sayıda interferogramla belirlenen deformasyon alanlarının dağıımının değerlendirildiği başlangıçtaki eski usül kullanımını 
tercih ettik. Bu vesileyle, Farksal İnterferometrik SAR (DInSAR) tekniği ile Fransız Uzay Araştırmaları Merkezi (CNES) tarafından üretilmiş, eski bir veri setinden Türkiye üzerine oluşturulan ilk interferogramları burada tanıtmayı ve bu interferogramlardaki deformasyon bulgularını Erzincan ovasındaki tektonik yapıların davranışlarıyla ilişkilendirmeyi hedefledik.

Erzincan havzasının tektonik yapısı esas olarak Barka ve Gülen (1989) ile Koçyiğit ve Rojay (1992a, b) çalışmalarında ele alınmıştır. Bu çalışmalar, KAF ile bunu havzanın doğu kesiminde oblik olarak kesen bir başka doğrultu atımlı fay olan Ovacık fayının (OF) her ikisinin de havzanın gelişiminden sorumlu oldukları sonucuna varmışlardır.

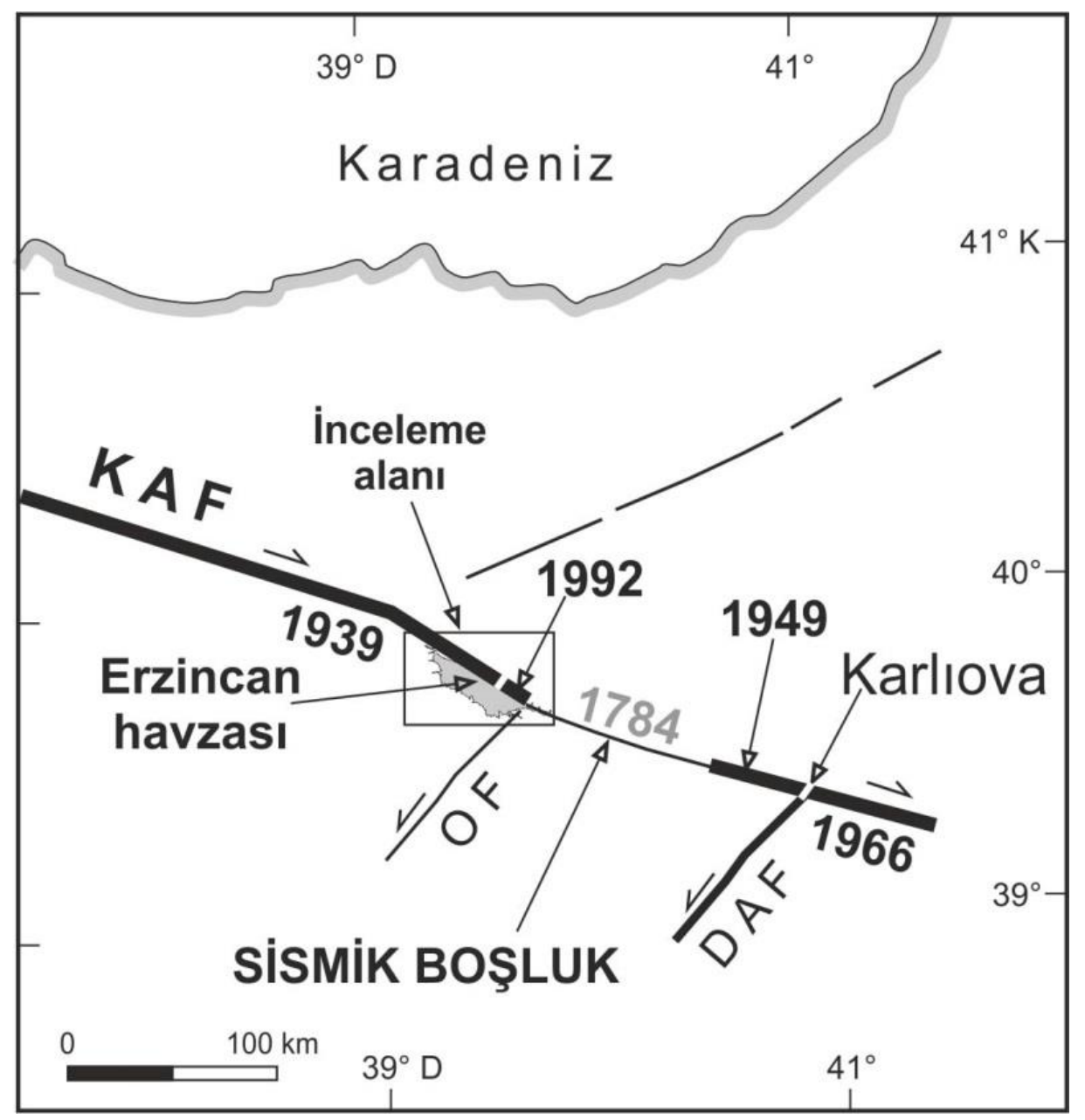

Şekil 1. İnceleme sahasının konum haritası (yapısal hatlar ve tarihler Barka,1996'dan alınmıştır). Kalın çizgiler, 1939, 1949, 1966 ve 1992 depremleri sırasında Kuzey Anadolu fayının kırılma bölgelerine karşılık gelir. 1992 ve 1949 kırıkları arasındaki sismik boşluğa dikkat ediniz. KAF: Kuzey Anadolu fayı; DAF: Doğu Anadolu fayı; OF: Ovacık Fayı.

Figure 1. Location map of the study area (structural lines and dates are from Barka, 1996). Heavy lines denote the North Anatolian Fault ruptures during the 1939, 1949, 1966 and 1992 earthquakes. Note the seismic gap between 1992 and 1949 segments. KAF: North Anatolian Fault; DAF: East Anatolian Fault; OF: Ovacık Fault. 
İnterferogramın yapısal yorumu, özellikle NAF-OF kesişim bölgesi hakkında daha ayrıntıı veriler gerektirdiğinden, SAR görüntü işleme çalışmaları sonrasında bir dizi saha çalışması gerçekleştirdik ve yüksek çözünürlükteki optik uydu görüntülerinin (SPOT Pankromatik band: $10 \mathrm{~m}$ ve Landsat TM: $\sim 30 \mathrm{~m}$ ) tektonik amaçlı stereoskopik analizlerini yaptık. Bunlara ilişkin ayrıntılı bilgiler bir akademik tez çalışmasında sunulmuş (Köse, 2000) ancak yayınlanmamıştır. Bu çalışmanın amacı, Türkiye'de büyüklüğü ve yarattığı hasarı en fazla olan depremi yaşamış Erzincan bölgemizle ilgili ilk interferogram çalışmalarını sunmak ve interferogram üzerinde belirlenmiş olan deformasyon alanlarını, önceki yapısal jeoloji çalışmaları ışı̆ında tartışmaktır.

\section{Erzincan Havzasının Genel Sismotektonik Özellikleri}

Erzincan havzası, Türkiye'nin doğusunda KAF ve OF kesişimine yakın bir tektonik çökme alanıdır. Önceki çalışmalar (Barka ve Gülen,1989; Koçyiğit ve Rojay, 1992b; Köse, 2000), havzanın KAF zonu boyunca çek-ayır tipinde bir açılmanın sonucu olarak oluştuğunu göstermektedir. OF aktivitesi havzayı genişletmektedir.

Erzincan tektonik çökme havzası içerisinde son yüzyılda iki yıkıcı deprem meydana gelmiştir (1939, M: 7.8-8.2 ve 1992, M:6.8).Çalışmamızda havzanın tektonik yapıları ve interferometrik bulgularıyla birlikte değerlendirilen bu depremlerin çeşitli kaynaklarda verilen farklı merkez üstü bilgileri Çizelge1'de sunulmuştur.

Türkiye'de aletli dönemde meydana gelen depremlerin en büyüğü en yıkıcısı olan 1939 Erzincan depremi (Mw: 7.8, Uluslararası Sismisite Merkezi - ISC; Di Giacomo vd., 2015; 2018), yerel zaman ile 27 Aralık 1939 tarihinde saat 01:57'de çok sert bir kış gecesinde meydana gelmiştir. Depremde 32962 kişi hayatını kaybetmiş, sadece Erzincan kent merkezinde yaklaşık rakamlarıyla 8000 kişi yaşamını yitirirken kent nüfusu 20000'den 12000'e düşmüştür. Yeri gelmişken, bu depremin önemli gördüğümüz bazı bilgilerini, oldukça zor şartlarda saha incelemesiyle üretilmiş hayranlık ve saygı uyandıran eski bir saha raporunu (Stchepinsky vd., 1940) çalışanlarını saygıyla anarak birincil kaynağından aktarmak ve araştırmacıları bu rapor hakkında kısaca bilgilendirmek istiyoruz.

Söz konusu rapor çalışması, depremle birlikte 27 Aralık 1939 tarihinde MTA (o dönemdeki eski adıyla Maden Tetkik ve Arama Enstitüsü, yeni adıyla Maden Tetkik ve Arama Genel Müdürlüğü) tarafından görevlendirilen bir araştırma ekibiyle yerinde saha çalışmasıyla gerçekleştirilmiştir (Stchepinsky vd., 1940). 
Çizelge 1. 1939 ve 1992 Erzincan depremlerinin (çizelgede ve haritalarda kısaca ve sırasıyla 39 ve 92 olarak verilmiştir) merkez üstleri. Kaynaklar: 1. Dewey (1976); 2. Soysal vd. (1981); Sipahioğlu (1983), 3. Fuenzalida vd. (1997).

Table 1. Epicenters of the 1939 and 1992 earthquakes (years are simplified in tables and figures as 39 and 92, respectively) according to 1. Dewey (1996) 2. Soysal et al. (1981); Sipahioğlu (1983) and 3. Fuenzalida et al. (1997).

\begin{tabular}{cccc}
\hline $\begin{array}{c}\text { Deprem } \\
\text { Ana Şoku }\end{array}$ & $\begin{array}{c}\text { Tarih }- \text { Saat } \\
\text { (gün.ay.yıl - saat:dakika) }\end{array}$ & $\begin{array}{c}\text { Merkez Üstü } \\
\text { (enlem, boylam) }\end{array}$ & Kaynak \\
\hline 39A & $27.12 .1939-01: 57$ (yerel) & $39.80^{\circ} \mathrm{N}, 39.38^{\circ} \mathrm{E}$ & 1 \\
$39 \mathrm{~B}$ & $27.12 .1939-01: 57$ (yerel) & $39.80^{\circ} \mathrm{N}, 39.50^{\circ} \mathrm{E}$ & 2 \\
92 & $13.03 .1992-20: 18$ (yerel) & $39.71^{\circ} \mathrm{N}, 39.63^{\circ} \mathrm{E}$ & 3 \\
\hline
\end{tabular}

Yaklaşık 4-5 ay sonra, 1940 Mayıs ayında raporlandırılan çalışmada, Erzincan şehrinin hemen doğusundaki Ekşisu yerleşkesi ile Sivas'ın Koyulhisar ilçesindeki Bahçe Köyü arasında, KAF zonu üzerinde çoğunluğu Kelkit vadisi boyunca BKB yönünde uzanan 185 km uzunluğundaki yüzey kırığı haritalaması ayrıntılı bir şekilde sunulmuştur (Şekil 2). Raporda, 1939 yılında depremle tamamen yıkılan Erzincan kent merkezi için, 8 km kadar BGB yönünde Köhnem Dağı'nın doğu eteklerinde Erzincan ovasına bakan düşük eğimli bir saha, yeni yerleşim alanı olarak önerilmiştir (Stchepinsky vd., 1940). Kemah boğazının girişinin kuzeybatısında, günümüzdeki Bahçeliköy ve Söğütözü (o dönemki isimleri sırasıyla, Hah ve Brastik; Stchepinsky vd., 1940) arasında bulunan bu saha önerisine karşın, Erzincan'ın yeni kent merkezi yıkılan kent merkezinin 3 km kadar kuzeyine, bugün bulunduğu yere taşınarak KAF zonuna daha çok yaklaştırılmıştır. Açıkçası, 1992 Erzincan depreminde yaşanan ağır yıkım ve can kaybının önemli bir kısmının temel nedeni, 1939 depreminden sonra bilim insanları ve araştırmacıların yapmış oldukları çalışma ve önerilerin bir şekilde gözardı edilmiş olmasıdır. 


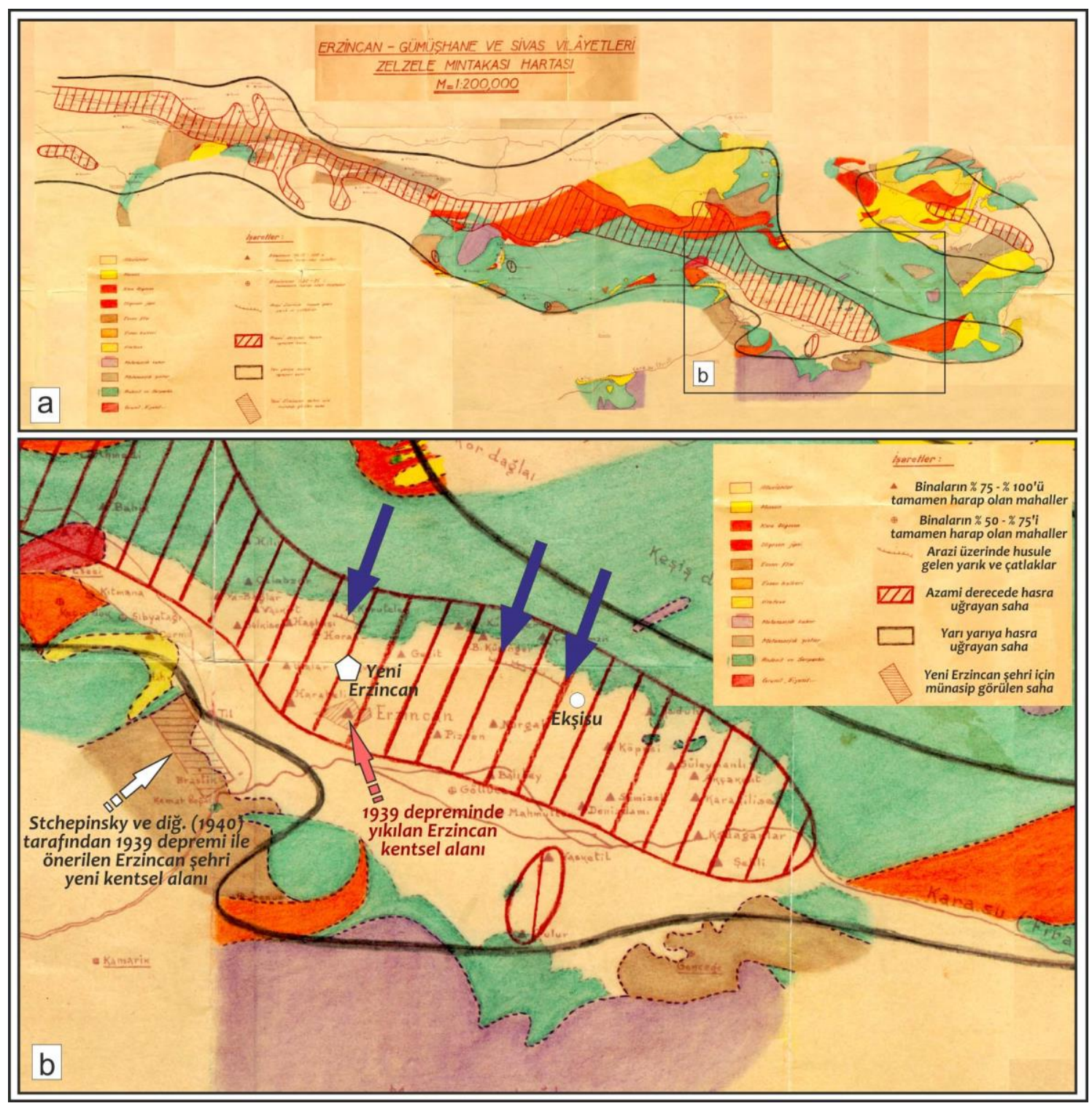

Şekil 2. a. 1939 Erzincan depremi için hazırlanmış deprem inceleme ve etki haritası (Stchepinsky vd., 1940'den aynen alınmıştır). Çizgili taranmış alanlar: deprem ile birinci derecede etkilenmiş bölgeler; Kalın siyah çizgi ile sınırlandırıımış alanlar depremin ikinci derecede etkilediği bölgeler. b- Aynı haritadan yakınlaştırılmış Erzincan havzası kesimi; tarafımızca yerleştirilmiş mavi oklar, havzada gelişmiş yüzey kırıklarına işaret etmektedir.

Figure 2. a. Original earthquake investigation and damage map prepared by Stchepinsky et al. (1940).Red stripped areas: areas affected by first degree damages; Areas limited by heavy black lines: areas with second degree damages. b. Erzincan basin area zoomed from map in inset (a), with blue arrows showing the earthquake surface ruptures.

Erzincan havzasının bir diğer ilgi çekici noktası ise, KAF boyunca fay kırığı incelemesiyle öne sürülen (Barka, 1992; Barka, 1996) bir sismik boşluğun varlığıdır (Şekil 3). Bu boşluk, 1992 Erzincan depremi fay kırığının en doğusundan başlayarak, KAF'nın Türkiye'nin doğusunda neotektonik bir ana kırık zonu olan (örneğin Arpat ve Şaroğlu, 1972) Doğu Anadolu Fayı (DAF) ile kesiştiği Karlıova ekleminin 
batısında meydana gelen 1949 depremi fay kırığının en batısına doğru, doğu yönünde uzanır (Şekil 3a). Bu hat, Erzincan havzasının doğu çıkışındaki Tanyeri ile Sansa arasında Sansa boğazı boyunca 22 km (Sansa Segmenti) ve Sansa ile Yedisu (Bingöl) arasında 53 km (Yedisu Segmenti) olmak üzere, BKB - DGD doğrultusunda uzanan toplam $75 \mathrm{~km}$ uzunluğunda iki ana fay segmentine karşılık gelmektedir (Şekil 3b). Batıdan doğuya doğru gidiş sırasıyla Yedisu segmentinin Sansa ile Uzunçayır arasında Kuzluca köyü yakınından geçen ilk 12 km'lik kısmı (Kuzluca alt segmenti), sismik boşluk hattının bütünü üzerinde önem arz eden olası bir kilitlenme alanı gibi görünmektedir. Sismik boşluk hattı en son 1784'te kırılmıştır (Ambraseys, 1975). Bu sismik boşluk zonu üzerinde yaklaşık 2 metrelik ötelenmenin sağlanacağı bir gerilme, o zamandan bu yana birikmiş olabilir (Barka, 1992). Coğrafi olarak, sismik boşluk hattının batı kesimini oluşturan Sansa segmenti Erzincan havzasının doğu kısımlarına karşılık gelmektedir ve çalışma alanımızın içine düşmektedir. Sansa segmentinin Tanyeri yakınındaki batı ucu, OF segmentlerinin KAF ile eklem yaptığı bir bölgede bulunmaktadır. Burası yine sismik boşluk hattının başladığı yer olarak olası bir kilitlenme morfolojisi sunmaktadır. Mevcut verileri, ayrıca bu bölgedeki deprem tahmin çalışmaları için yararlı olabilecek bir şekilde ele alacağız.

1992 Erzincan depremi ise (Mw: 6.65, ISC; Di Giacomo vd., 2015; 2018), yerel zaman ile 13 Mart 1992 tarihinde saat 19:18'de meydana gelmiş ve depremde 653 kişi hayatını kaybetmiştir. Çalışmamızda, DInSAR metodolojisini, bu yıkıcı deprem sonrasındaki 2.5 yıllık postsismik dönemde devam eden yerdeğiştirmeleri incelemek için kullandık. Deprem merkez üssü (Fuenzalida vd., 1997), havzanın KAF'na paralel bir fay segmenti boyunca, KAF ana izinin güneyinde, lokal bir çek-ayır yapısının kuzey sınırında (Şekil 4b) yer almaktadır (Köse, 2000). Deprem fayının transtansiyonel karakteri (Fuenzalida vd., 1997) uydu görüntüsü analizleri ile de uyumludur. Artçı şoklar, havzanın doğu kısımlarına, KAF'nin OF ile eklem yaptığı yerin yakınlarına doğru göç etmiştir.

\section{ERZINCAN HAVZASININ DInSAR ANALIZLERI}

Bu çalışma, Erzincan havzasında 1993-1995 yılları arasındaki post-sismik dönemi kapsamaktadır ve bu süre zarfında incelenen alanda göz önünde bulundurulacak büyüklükte herhangi bir deprem kaydedilmemiştir. ERS-1 uydusunun, biri yörünge çıkış yönüne ve diğeri iniş yönüne karşılık gelen iki SAR görüntü çifti, Fransa Uzay Araştırmaları Merkezi (CNES) radar bölümünde, Farksal İnterferometrik SAR (DInSAR) tekniği kullanılarak işlenmiş ve iki adet farksal SAR interferogramı üretilmiştir. 1/25000 ölçekli 25 adet topografik harita paftasının sayısallaştırılmasıyla Hacettepe Üniversitesi'nde üretilmiş olan yüksek çözünürlüklü bir sayısal yükseklik modeli (DEM; Şekil 4a), ERS-1 uydusunun Sentez Açılımlı Radar (SAR) görüntülerinin işlenmesindeki çeşitli aşamalarda ve 


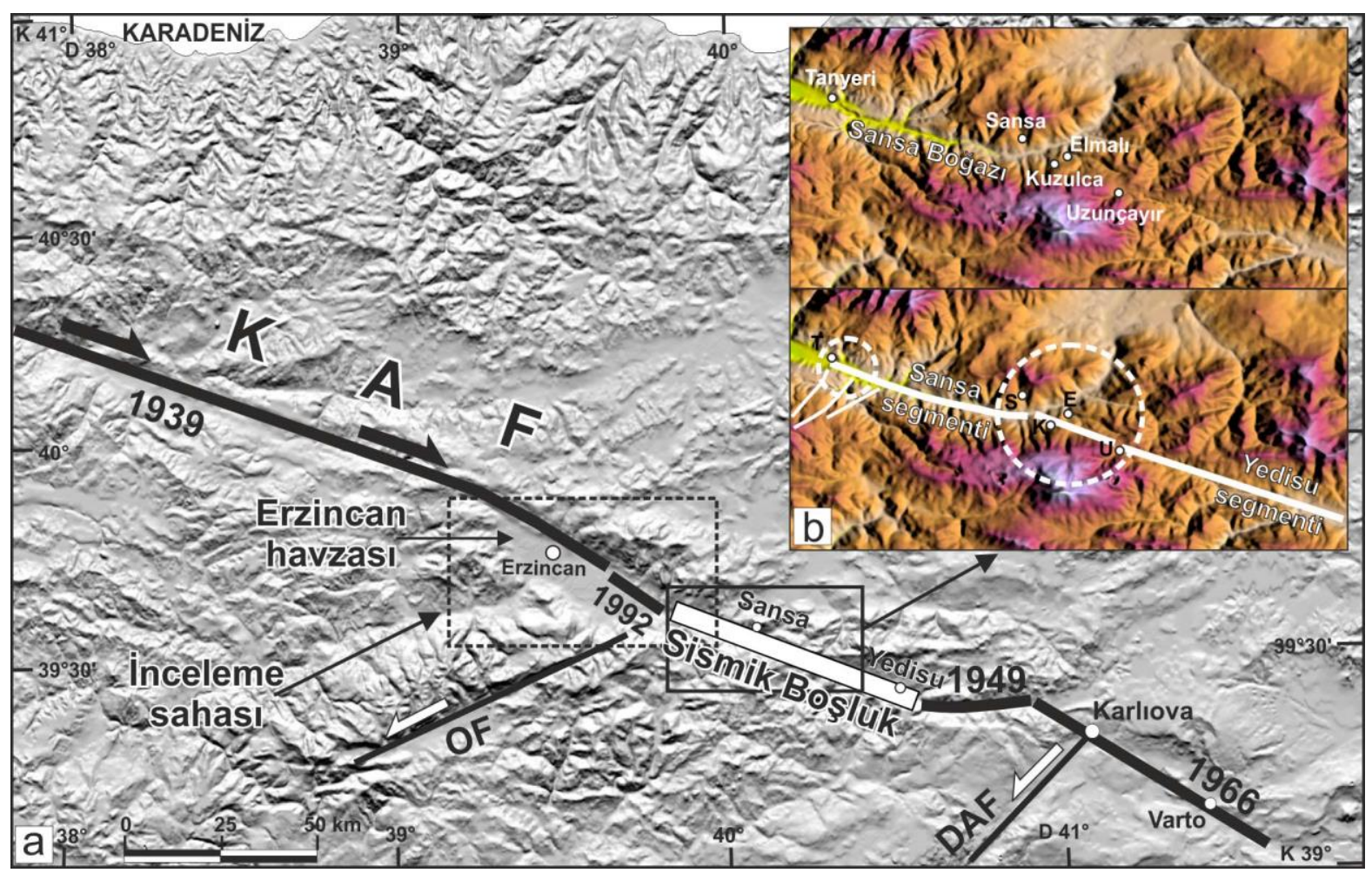

Şekil 3. a. Çalışma bölgesinin çevresinde son yüzyıldaki depremlerle KAF segmentleri üzerinde gelişen yüzey kırıklarını (siyah kalın çizgiler) gösteren harita (Stchepinsky vd., 1940, Koçyiğit ve Rojay 1992b, Barka 1996'dan derlenmiştir). KAF: Kuzey Anadolu fayı; DAF: Doğu Anadolu fayı; OF: Ovacık fayı. b. İnceleme alanının doğu kesiminde sismik boşluk zonundaki Sansa ve Yedisu segmentleri. Kesik çizgili daireler sismik boşluk zonundaki olası kilitlenme bölgelerini göstermektedir.

Figure 3. a. Map showing the earthquakes and surface ruptures in and near the study area during the last century along the North Anatolian Fault (compiled from Stchepinsky et al., 1940; Koçyiğit and Rojay 1992b and Barka 1996). KAF: North Anatolian Fault; DAF: East Anatolian Fault; OF: Ovacık Fault. b. Sansa and Yedisu segments in the seismic gap at the east of the study area. Dashed lines circles are probable locking zones in the seismic gap.

üretilen interferogramlardan topografik katılımların giderilmesinde kullanılmıştır. Her iki interferogramın atmosferik, topografik, yörüngesel ve benzeri dış katılımlardan arındırılma aşamaları CNES’te gerçekleştirilen çalışmalarla yapılmıştır.

\section{İnterferometrik Verilerin Tanıtımı}

Sentez açılımlı radar (SAR) tekniğinin yörüngelendirilmiş radar uyduları ile düzenli olarak sağlanan verilerden itibaren yeryüzündeki deformasyonlara yönelik kullanımının hayata henüz geçirildiği bir dönemde, bir depremin sergilediği yüzey deformasyonları, ilk kez Massonnet vd. (1993) tarafından, ABD'nin batısındaki Landers depremi $(M=7.3)$ için ERS-1 uydusu verileri kullanılarak radar 


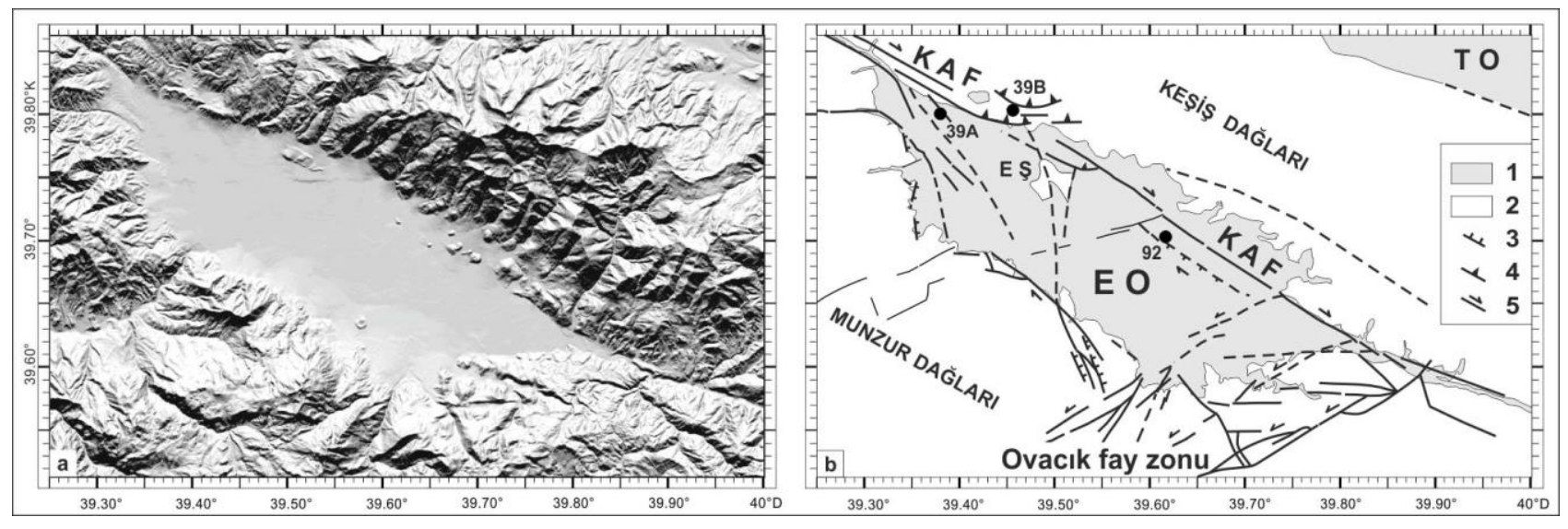

Şekil 4. a. İnceleme alanının yüksek çözünürlüklü sayısal arazi modelinin yapay ışıklandırma rölyef görüntüsü (Köse, 2000). b. Çalışma alanının yapısal jeolojisi (Barka ve Gülen,1989; Koçyiğit ve Rojay,1992b; Köse, 2000'den derlenmiştir). İri siyah noktalar Çizelge 1'de verilen deprem merkez üssü konumlarını göstermektedir. Lejant anahtarı: 1) Kuvaterner kayaçlar, 2) Temel kayaçlar, 3) Normal fay, 4) Bindirme fayı, 5) Doğrultu atımlı fay. EO: Erzincan ovası; EŞ: Erzincan şehri; KAF: Kuzey Anadolu fayı; TO: Tercan ovası.

Figure 4. a. Artificially illuminated high-resolution digital elevation model prepared from digitized 1/25.000scale topographic maps of the study area (Köse, 2000). b. Structural geology map of the study area (compiled from Barka and Gülen, 1989; Koçyiğit and Rojay, 1992b; Köse, 2000). Big black dots correspond to epicenters with locations given in Table 1. Legend key: 1) Quaternary rocks; 2) Basement rocks; 3) Normal fault; 4) Thrust fault; 5) Strike-slip fault. EO: Erzincan Basin; EŞ: Erzincan City; KAF: North Anatolian Fault and TO: Tercan Plain.

interferometrisi tekniğiyle haritalanmıştır. Bununla birlikte, bir uzay jeodezisi tekniği olarak jeolojik uygulamalar alanında yeni bir çığır açan metodolojinin bu ilk uygulamaya geçtiği dönemde, dünya genelinde kullanılan bilgisayarların işlem kapasitesi günümüze göreceyle oldukça yetersizdi. “Hesap yapma bazında SAR tekniği, 300 milyar civarında matematiksel işlem gereksinimiyle oldukça üst düzeydedir. ...Yeryüzünde 100 km x 100 km boyutlarında bir alana karşılık gelen bir radar görüntüsü, tipik iş istasyonları kullanılarak 1990’lı yılların ortalarında (sentez açılımıyla) yaklaşık bir saatte oluşturulmaktaydı" (Massonnet ve Feigl, 1998). Bu nedenle 1990'lı yılların ortalarında teknik, genellikle CNES ve NASA gibi başlıca ileri araştırma kuruluşlarınca uygulanmaktaydı.

Massonnet vd. (1993) tarafından yayınlanan çalışmanın hemen ardından CNES ile temasa geçerek, 1992 depreminin henüz atlatmış olan Erzincan havzası için farksal interferogram oluşturulması talebinde bulunduk. Kuruluşun kendi çalışmaları dışında, çeşitli kurumların benzer taleplerindeki yoğunluk nedeniyle üç yıl kadar bir beklemenin ardından, uydusal verilerden aşağıda sunmuş olduğumuz Türkiye üzerine DInSAR tekniğiyle üretilmiş ilk interferogramlar 1996 yılında tarafımıza sağlanmıştır. Üretilen iki adet farksal interferogram, iki çift ERS-1 radar görüntüsünden DIAPASON işlem yazılımı zinciri kullanılarak oluşturulmuştur (Çizelge 2). 9 Haziran 1993 (9928 yörünge no) ile 
15 Eylül 1995 (21795 yörünge no) arasındaki dönemi içeren ilk interferogram, 5376.47 m düzeyinde oldukça iyi bir eşlem yüksekliği değeriyle iniş yönlü görüntü çiftinden hesaplanmıştır (Şekil 5a). 25 Nisan 1993 (9291 yörünge no) ile 10 Ekim 1995 (22661 yörünge no) arasındaki dönemi içeren ikinci interferogram, -12845.12 m olan mükemmel bir eşlem yüksekliği değeriyle çıkış yönlü görüntü çiftinden hesaplanmıştır (Şekil 5b).

Çizelge 2. Erzincan havzası farksal interferometri çalışmalarında kullanılan ERS-1 SAR görüntüleri.

Table 2. ERS-1 SAR images used in differential interferometric research of the Erzincan Basin.

\begin{tabular}{ccccc}
\hline Görüntü çifti & görece yüksekliği & yörünge kayıt no & kayıt tarihi & yörünge yönü \\
\hline \multirow{2}{*}{ 1. çift } & \multirow{2}{*}{$5376.47 \mathrm{~m}$} & 9928 & 9 Haziran 1993 & iniş \\
& & 21795 & 15 Eylül 1995 & iniş \\
\hline \multirow{2}{*}{ 2. çift } & $-12845.12 \mathrm{~m}$ & 9291 & 25 Nisan 1993 & çıkış \\
& & 22661 & 10 Ekim 1995 & çıkış \\
\hline
\end{tabular}

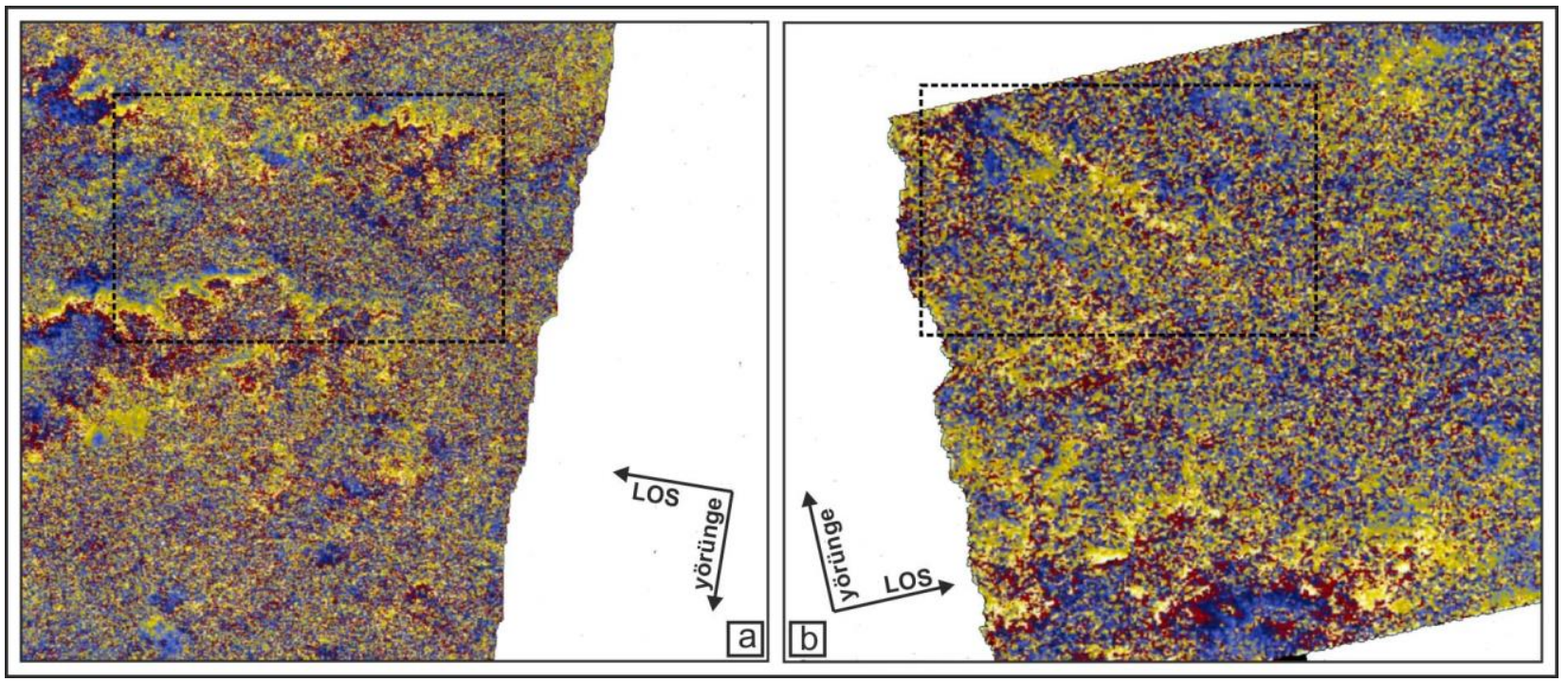

Şekil 5. Türkiye üzerine üretilmiş ilk farksal interferogramlar (siyah kesik çizgili dikdörtgenler inceleme alanını göstermektedir). a. 9928 ve 21795 yörünge kayıtlı (09.06.1993 - 15.09.1995) ERS-1 SAR görüntü çiftinden üretilen farksal interferogram. b. 9291 ve 22661 yörünge kayıtı (25.04.1993 - 10.10.1995) ERS-1 SAR görüntü çiftinden üretilen farksal interferogram.

Figure 5. The first differential interferograms prepared for Turkey (black dotted lined rectangles denote the study area). a. Differential interferogram produced using the twoERS-1 SAR images (9928 and 21795 orbit recorded, 09.06.1993 and 15.09.1995); b. Differential interferogram produced using the twoERS-1 SAR images (9291 and 22661 orbit recorded, 25.04.1993 and 10.10.1995). 
Eşlem yüksekliği ve yapılan düzeltmeler göz önüne alındığında, diferansiyel interferogramlarda kalıntı topografik artefakt yoktur. Faz farklarına olan dış katılımların giderilmesine yönelik çalışmalarda her iki interferogramda da aynı DEM verisi kullanılmıştır. Buna karşın iniş yönlü görüntü çiftine ilişkin interferogramda, birçok örge yapısı belirmiştir (Şekil 5a). Bunlar topografyayı takip ediyor olmakla birlikte, atmosferik olaylarla bağlantılı oldukları kesindir; çünkü çıkış yönlü görüntü çiftinden oluşturulan interferogramda bulunmamaktadırlar (Şekil 5b). Çok iyi eşlem yükseklik değerlerine ve yüksek çözünürlüklü bir sayısal arazi modeline rağmen, hesaplanan interferogram görüntülerinde gürültü mevcuttur; özellikle interferogramlardan birinde (9928 - 21975 yörünge eşleminde) belirli bir tutarlılık eksikliği göze çarpmaktadır. Bunun, 9928 - 21975 yörüngelerinin interferometrik eşlemesindeki iki SAR görüntülemesinin nispeten uzak zaman aralıklarında yapılmış olmasından (2 yıl ve 2,5 yıl) kaynaklandığı düşünülmüştür. Olasılıkla bu farklı zamanlardaki iki görüntülemenin, lokal meteorolojik koşullar ve/veya yüzey ve toprak özelliklerinin (bitki örtüsü, nem, kar vb.) birbirine göreceyle üst düzey farklılıklar gösterdiği bir zamanlamaya denk gelmiş olmaları yüksek bir ihtimaldir. Çok gürültülü interferogramlarda artefaktlar ile gerçek deformasyonlar arasında ayrım yapmak zordur (Massonnet vd, 1995). Bu nedenle, üzerinde giderilemeyen atmosferik katılımlara ilişkin kalıntı artefaktların oluştuğu söz konusu farksal interferogramın (9928 - 21975 yörünge eşlemi) çalışmada değerlendirmeye alınmamasına karar verilmiştir.

Diğer interferogramda (9291 - 22661 yörünge eşlemi) ise tamamlanmış bir örge dizilimi oluşmamakla birlikte, bir örgenin alt mertebelerinde yerdeğiştirmeleri yansıtan deformasyon alanlarının geliştiği belirlenmiştir. Deformasyonların küçük olduğu bir interferogramda örgeler kısmidir (dalga boyunun yarısından az). Bu nedenle yerdeğiştirmelerin gradyanının anlaşılması zordur. Gürültülü farksal interferogramlarda bu zorluk artar. Analiz eden kişinin, olayı görsel olarak yorumlamasını sağlayan bir renk paleti kullanabilmek önemlidir. Bu renk paletinde her faz verisi için özel bir renk tonu atanır. Faz sıçramalarının belirli bir renkle işaretlendiği ve ara fazlanmaların yakın renk aralıklarına yerleştirildiği renk ölçeğindeki diferansiyel interferogramların renkli ifadeleri genellikle daha iyi bir görsel yorum yapılmasını sağlamaktadır.

\section{İnterferometrik Bulguların Morfolojik Değerlendirilmesi}

Büyüklüğü $M=7.3$ olan bir depremle açığa çıkan enerjinin meydana getirdiği deformasyonları haritalayan Massonnet vd. (1993) tarafından gözlenen çok sayıdaki örge yapısının, tahmin edildiği üzere postsismik kısa bir dönem için üretilen bu interferogramlarda gözlenmesi beklenemezdi. Bununla birlikte, interferogramlardan birinde, tamamlanmamış bir örgenin alt seviyeleri açıkça takip edilebilmektedir (Şekil 6a). ERS-1 kaynaklı interferogramlarda bütünsel bir örge yapısının, uydunun yere bakış doğrultusunda (LOS) $28 \mathrm{~mm}$ (ERS radar sinyalinin dalga boyu yarı uzunluğu) 
büyüklüğünde zemin deformasyonlarına karşılık geliyor olması nedeniyle, çalışmamızda bir örgenin alt seviyelerinde deformasyonların belirlenmiş olması durumu, araştırma döneminde toplam deformasyon miktarının 28 mm'ye ulaşmadığı anlamına gelmektedir. Bu deformasyon alanlarının (Şekil 6a) havzanın DEM rölyef görüntüsüyle (Şekil 4a) ilişkilendirilmesi (Şekil 6b), bunların havza (Erzincan ovası) sınırlarında gelişmiş olduklarını ortaya koymaktadır. Bir interferogramın doğrudan yorumlanması ancak bütünsel örgelerle yapılabilir. Çok gürültülü bir interferogram üzerinde kısmi bir örgenin yorumlanması için, bilginin morfolojiyi yansıtan bir rölyef üzerinde tartışılması gerekir.

Erzincan ovası ve yakın çevresini kapsayan inceleme alanına yönelik olarak, çıkış yönlü interferogram (Şekil 6a), DEM ile rölyeflendirilmiş interferogram (Şekil 6b), gelişen deformasyonların çizildiği interferogram (Şekil 6c) ve yapısal jeoloji haritası (Şekil 6d) Şekil 6'de sunulmaktadır. İlk aşamada, interferogramın (Şekil 6a) ve havza topografyasının (Şekil 6b) karşılaştıııması, havza şeklinin interferogramda neredeyse bir bütün olarak göründüğünü ortaya koymaktadır (Şekil 6c). Havzanın kuzey sınııında, kuzey batıdan güneydoğuya doğru geçiş sırasıyla, ağırlıklı olarak mavi renkli piksel kümelenme bölgesi ile (Şekil 6c'de MZ) ağırıklı olarak sarı renkli piksel bölgesi (Şekil $6 c^{\prime}$ de SZ) deformasyona karşılık gelen alanlar olarak işaretlenmiştir (Şekil 6c). Daha az belirginlikteki $A Z$ bölgesi, $M Z$ bölgesini daha doğuda sürdürüyor gibi görünmektedir. Bu bölgeler ( $A Z$ ve $M Z$ ), inceleme döneminde benzer yerdeğiştirme oranlarılya hareket eden yer pikselleri ile temsil edilmektedir. Yapısal jeolojiyle olan ilişkilerine bir sonraki bölümde değineceğiz.

Güney sınırı daha dar ve nispeten daha homojen ve ağırlıklı olarak mavi renkli bir piksel bölgesi boyunca açığa çıkmışıิır (Şekil 6c'de GS). Her iki sınırla ilişkili deformasyon alanları, havzanın doğu kısımlarında kaybolur ve doğuda daha fazla gözlenmez. Doğrultu ve interferometrik yapılanma olarak GS'na benzer bir başka bölge, interferogramın kuzey-doğusunda belirgindir (Şekil 6c'de TZ). Bu yapı, Kuvaterner Tercan Ovası'nın güney kenarını sınırlandırmaktadır (Şekil 6d'de TB).

Çıkış yönlü interferogramın kısmi örgelerine karşılık gelen homojen piksel kümeleşmeleri, bölgenin genel faz değişimine kıyasla artan bir faz farkını gösterir. Bununla birlikte, tamamlamış örge yapısının olmaması, yerdeğiştirme gradyanının belirlenmesini mümkün kılmamaktadır. Dolayısıyla, LOS doğrultusundaki hareketin hangi yöne olduğuna yönelik bir bilgi interferogramın mevcut haliyle önerilemez. Bununla birlikte, sahada ayrıntı veren önceki çalışmaların verileri dikkate alınarak (Barka ve Gülen, 1989; Tatar vd., 1993; Pınar vd, 1994; Chorowicz vd., 1995; Nalbant vd., 1996; Fuenzalida vd., 1997, Köse, 2000), belirlenen hareketlerin bir çökmeye karşlık geldiği söylenebilir. 


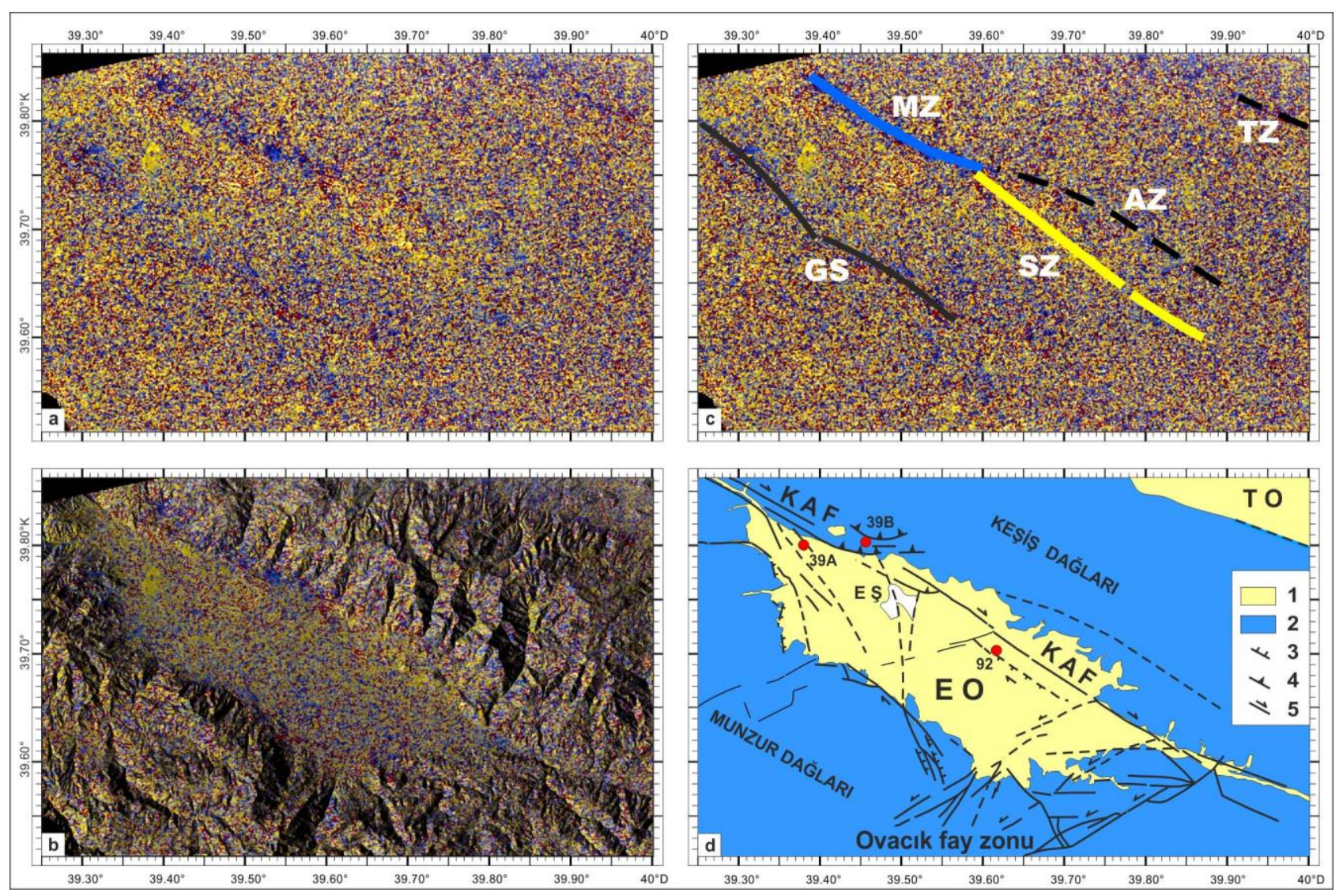

Şekil 6. a. Erzincan havzasının 25 Nisan 1993 ve 10 Ekim 1995 tarihli iki ERS-1 radar görüntüsünden elde edilen interferogramı. b. İnterferometrik piksel kümelenmelerinin DEM rölyef görüntüsü ile havza morfolojisi üzerinde görünümü. c. Metinde tartışılan ve $A Z, G S, M Z, S Z$, and TZ olarak kodlanan piksel kümelenmelerini gösteren harita. d. (b) ve (c) haritalarında gözlemlenen piksel küme hatlarının yapısal hatlarla karşılaştırılması için Şekil 4.b'de verilen yapısal jeoloji haritası eklenmiştir. Kırmızı noktalar Çizelge 1'de verilen deprem merkez üstlerini göstermektedir. Şekil 7'de interferometrik hatların yapısal hatlarla ilişkisi daha geniş bir haritada gösterilmiştir.

Figure 6. a) Interferogram of the Erzincan basin, produced from ERS-1 radar pair acquired in 25 April 1993 and 100ctober 1995. b) Composite image of the interferogram and DEM showing interferometric pixel clusters on the morphology of the basin. c) Composite image of the interferogram and the map showing the clustered pixel alignment zones, denoted by $A Z, G S, M Z, S Z$, and $T Z$, discussed in text. d) Structural geology of the study area, as in Figure 4b, to compare interferometric data with structural data. Key to legend is the same as in Figure 4b. A larger map is given in Figure 7.

\section{Interferogram ve Havzanın Yapısal Jeolojisi}

Burada, interferogramda ortaya çıkan deformasyon alanlarını, havzanın daha önceki çalışmalarda (Barka ve Gülen,1989; Koçyiğit ve Rojay, 1992b; Köse, 2000) ayrıntıları verilmiş olan yapısal jeolojisi 
ile bağlantılı olarak ele almaktayız. Aşağıda, interferometri bulgularını bu araştırmacıların ortaya koydukları yapısal düşüncelerle ilişkilendiriyoruz:

a) Transpresyonel bir bölge, havzanın kuzeybatı kısımlarında etkinlik göstermektedir. Bu bölge, interferogramda $M Z$ ile gösterilen deformasyon bölgesine karşılık gelmektedir. MZ bölgesi, KAF segmentlerinin jeolojik haritalamasında (örneğin, Koçyiğit ve Rojay, 1992b) olduğu gibi, Erzincan şehrinin hemen kuzeyinde, transpresyonu öneren bir fay izi geometrisi sunmaktadır. Burası büyük bir olasılıkla yıkıcı 1939 depreminin (M = 8.0, Barka, 1996) meydana geldiği bölgedir (Şekil 6d).

b) Bu bölge, daha doğuda, SZ ile gösterilen deformasyon alanına geçiş yapmaktadır. 1992 depreminin (M: 6.8) merkez üssü bu bölgenin yakınında bulunmaktadır (Şekil 6d). Bu depremin odak mekanizması, merkez üssünün doğusundaki bir KAF segmenti boyunca kinematik göstergelerin saha incelemeleri, KAF uzanımlı riyolitik domların varlığı ve uydu görüntüsü analizleri, KAF'nın bu lokal kesimi boyunca transtansiyonel fay hareketleri olduğunu önermektedir (Fuenzalida vd., 1997; Köse, 2000).

c) Havzanın kuzey ve güney sınırlarının morfolojik özellikleri üzerine yapılan önceki çalışmalarda, güney sınırın tektonik olarak daha az aktif olduğu öne sürülmektedir (Barka ve Gülen, 1989; Köse, 2000). Güney sınırının göreceyle daha zayıf olan interferometrik işareti bu görüşleri desteklemektedir.

d) İnterferogramda havza sınırları çevresinde izlenen deformasyon alanları, havza sınırlarının OF zonu ile kesişme bölgesinin yakınlarında gözden kaybolmaktadır. Bu, büyük olasılıkla sismik boşluk zonuna yaklaştıkça KAF segmenti boyunca gelişen kinematik değişimin bir sonucu olmalıdır. Bu kinematik değişim, KAF/OF ekleminin yakınında sismik boşluğun batı ucuna yaklaşırken KAF boyunca kayma hızlarının düşmesiyle ilişkili olabilir (Şekil 7).

\section{SONUÇLAR VE TARTIŞMA}

1. Erzincan havzası için hazırlanan interferogram, tamamlanmamış bir örgenin bir miktar alt seviyelerindeki büyüklüklerde deformasyonları içermektedir ve bunlar nispeten homojen renkli piksel kümeleri ile belirginleşmiştir. Basitçe bir özetle, interferogramların hazırlanmasında kullanılan metodolojiye göre, aynı kümelenme kuşağı üzerinde aynı piksel değeri veya renk tonuyla temsil edilen noktalar, uydu doğrultusunda aynı yönde ve aynı miktarda yerdeğiştirmeye ilişkin benzer hareketler gösterirler. İnterferogramın yapısal jeoloji haritası ile karşılaştırılması, interferogramda 
ortaya çıkan deformasyon alanlarının aynı zamanda havzanın yapısal zonlarına karşılık geldiğini kanıtlamaktadır.

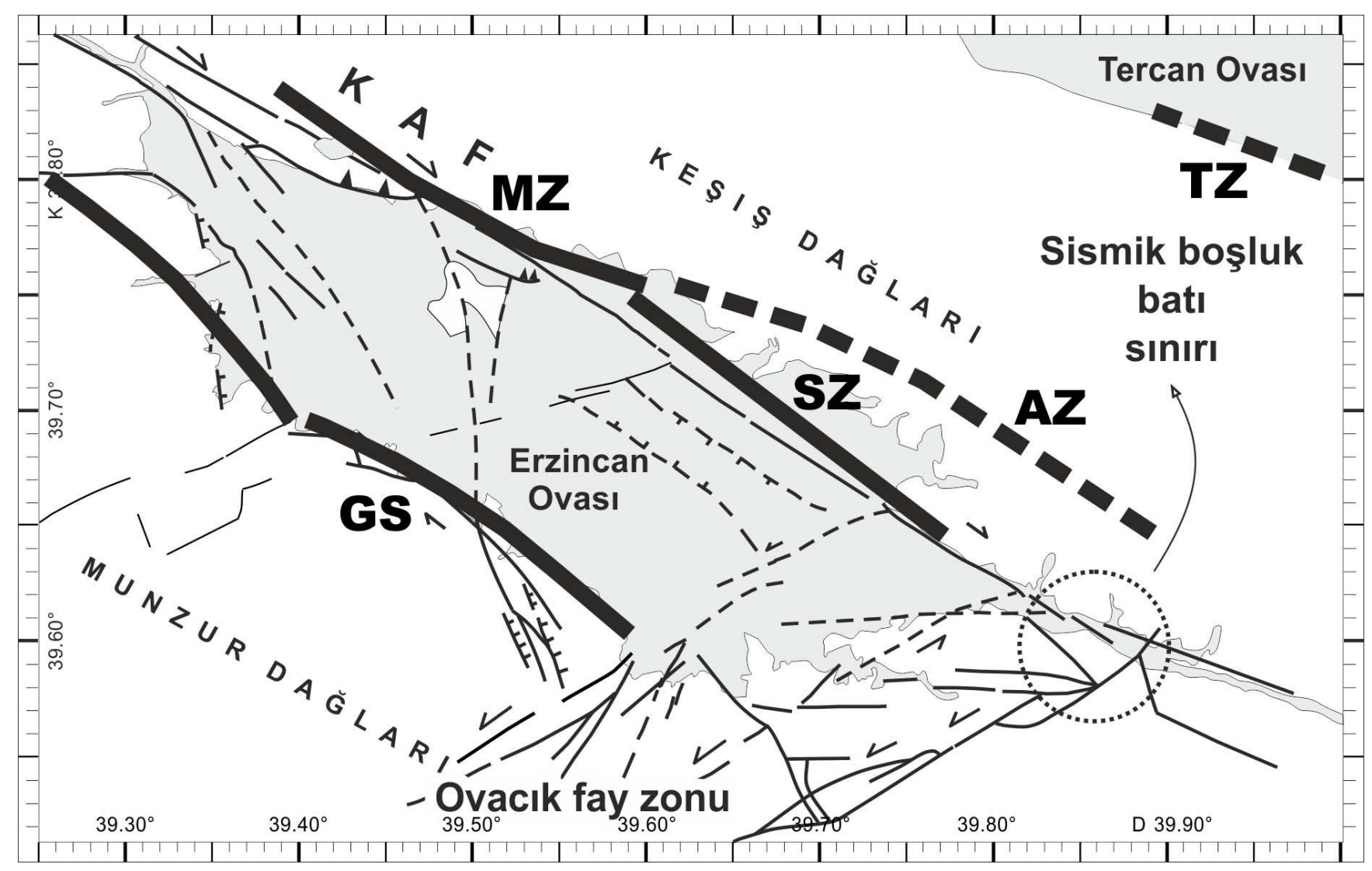

Şekil 7. Kalın çizgilerle gösterilen interferometrik zonlarla yapısal hatların (bakınız Şekil 4b) ilişkisini gösteren harita. Kuzey Anadolu Fay (KAF) segmentlerinin interferometrik uzanımları, KAF zonunun Ovacık Fay Zonuyla olan kesişme zonunun doğusunda gözlenmemektedir. Sismik boşluk dolayısıyla kesik çizgili daire ile gösterilen bu eklem zonunun doğusuna doğru uzanmaktadır.

Figure 7. The interferometric zones, drawn in heavier lines, superimposed to the structural map of Fig. $4 b$. Movements of the NAF segments are not observed east of their junction with the Ovacık fault zone. The seismic gap therefore extends eastwards from this junction, represented by a dashed circle.

2. İnterferogram görüntüsünün bütününe bakıldığında, özellikle kuzey kesimdeki KAF'na paralel sınırlar için daha belirgin olmak üzere, havzanın şekli kolayca ayırt edilebilmektedir. Bu, inceleme dönemi içerisindeki havza evriminde KAF'na paralel hareketlerin egemen olduğunu göstermektedir. OF zonunun hareketleri, muhtemelen bu kırık boyunca çok daha küçük olan kayma hızları nedeniyle, interferometrik analizlerde dolaylı olarak izlenim vermemektedir. 
3. Havzanın kuzey sınırı ile karşılaştırıldığında, güney sınırı, interferogramda daha dar bir piksel bölgesi ile temsil edilmektedir. Bu, güney sınırının tektonik olarak kuzey emsalinden daha az aktif olduğu sonucunu veren önceki morfo-tektonik çalışmalarla uyumludur.

4. Havzadaki yer hareketlerinin, sismik açıdan sessiz olan bir dönem içinde tespit edilmiş olması ilginç bir noktadır. Fay zonundaki yerdeğiştirmeler, asismik bir deformasyonla ve/veya sismik ancak büyüklüğü küçük olan depremlerle sağlanmış olmalıdır.

5. KAF hareketlerinin KAF-OF ekleminin doğusunda devam etmediğinin gözlenmesi, sismik boşluğun batı kısmında olasılıkla KAF'nın kayma hızındaki bir düşüşü yansıtmaktadır. Bu eklem bölgesi, kırık zonu boyunca bir 'kilitleme noktasına' karşılık gelebilir. Burada veya daha doğuda ve sismik boşluk içerisinde biriken gerilme, gelecekte depremler tarafından serbest bırakılacaktır.

6. İnterferometri çalışması, önemli bir depremselliğin yaşanmadığı postsismik bir dönemde, aktif tektonik ortamında ilginç sonuçlar vermiştir. Çalışmada aktif fay segmentleri tespit edilmiş ve segmentlerdeki hareket farklılaşmasına bağlı olarak farklı kabuk davranışları önerilmiştir. Ayrıca, havzanın doğu kesiminde KAF boyunca fay hareketlerinin farklılaşması (hızların ve yerdeğiştirmelerin sönümlenmesi), bir fay segmentinin kaymaların engellendiği bir sismik boşluk zonuna yaklaştığında beklenenlerle uyumludur. İnterferometri, böyle bir olayı deprem tahmin alanında incelemek için etkili bir tamamlayıcı araç olabilir.

7. Bu çalışmada kullanılan ilk radar görüntüsünün alınma zamanından (1993) bu yana 25 yılın üzerinde bir süre geçmiştir. Yaklaşık 20 mm.y ${ }^{-1}$ hızla kabuk yerdeğiştirmelerinin yaşandığı bir alanda (GPS ölçümleri, Reilinger vd., 1997), intersismik dönem boyunca interferometrik örgelerin gözlemlenmesi büyük bir olasılıktır (Farksal SAR interferogramlarında, uydu bakış doğrultusundaki zemin yerdeğiştirmeleri kullanılan dalga boyunun yarısına ulaştığında - ERS uyduları için $\lambda / 2=28$ mm - tamamlanmış bir örge oluşur). Son 25 yıl içerisinde farklı dalga boylarında veri kaydeden çok sayıda radar uydusu yörüngelendirilmiştir. Bunların veri arşivlerinden dünyanın birçok yerinde olduğu gibi KAF zonu üzerinde de çok sayıda InSAR çalışması yapıImıştır (örneğin, Wright vd., 2001; Walters vd., 2011; Cakir vd., 2014; Cavalié ve Jónsson, 2014; Walters vd., 2014; Hussain vd., 2016a; Hussain vd., 2016b; Hussain vd., 2018). KAF üzerinde yapılan bu son dönem InSAR çalışmaların çoğu, genellikle yüzlerce km uzunlukta binili komşu yörünge verilerinin entegre edildiği yüzlerce km genişlikteki alanlar için yine yüzlerce interferogram yığını ile, ağırlıklı olarak bölgesel ölçekteki hız ve gerilim alanlarına yönelik gerçekleştirilmiştir. Faaliyetini tamamlamış ve faaliyetine devam eden radar uydularının görüntü arşivlerinden yapılacak büyük ölçekli (lokal veya havza odaklı) InSAR 
çalışmalarının, farklı ölçekteki fayların davranışlarının belirlenmesine önemli katkılar sağlayacağını düşünmekteyiz. Özellikle KAF'nın Sansa ve Yedisu segmentleri gibi sismik boşluk özelliği gösteren fay segmentlerine yakın odaklanmış InSAR gözlemleri, bu zonlar üzerinde zaman olarak yakınlaşan olası çok yıkıcı depremlerin öngörülmesinde ve sergileyecekleri zararların en aza indirgenmesinde eşsiz bir öneme sahip olabilecektir.

\section{KATKI BELIRTME}

Bu çalışma kısmen TUBITAK/CNRS-243 sayılı Türkiye-Fransa Bilimsel İşbirliği projesi ile desteklenmiştir. Yazarlar, çalışmada kullanılan interferogramları ilgili dönemde hazırlayan ve işleyen Hélène Vadon ile CNES radar bölümüne şükranlarını sunar. Van Yüzüncü Yıl Üniversitesi'nden sayın Zühre Şentürk çalışmanın yayına hazırlanmasında itici güç olmuştur, kendisine teşekkür ederiz. İki hakemimiz çok verimli bir şekilde katkıda bulunmuşlardır, kendilerine müteşekkiriz. Son olarak, arazi çalışmalarımız sırasında tanıma şerefine ulaştığımız, deprem konusuna olan merakını takdir etmiş olduğumuz, müstesna şahsiyeti ile unutulmayacak valimiz, müteveffa Recep Yazıcıoğlu beyefendiyi saygı ve sevgi ile anıyoruz.

\section{KAYNAKLAR}

Ambraseys, N.N.,1975. Studies in historical seismicity and tectonics. In: Geodynamics of today, The Royal Soc. London, 7-16.

Arpat, E. and Şaroğlu, F., 1972. The East Anatolian fault system: Thoughts on its development (in Turkish). Maden Tetkik Arama Ens. Derg., 78, 33-39.

Barbot, S., Lapusta, N. and Avouac, J.-P., 2012. Under the hood of the earthquake machine: Toward predictive modeling of the seismic cycle. Science, 336 (6082), 707-710.

Barka, A., 1992. The North Anatolian fault zone. Annales Tectonicae, spec. issue, suppl. to vol. VI, 164-195.

Barka, A., 1996. Slip distribution along the North Anatolian Fault associated with the large earthquakes of the period 1939 to 1967, 1996. Bull. Seism.Soc. Am., vol. 86, no. 5, pp. 12381254.

Barka, A.A. and Gülen, L., 1989. Complex evolution of the Erzincan basin (eastern Turkey). J. Struct. Geol., Vol. 11, No. 3: 275-283. 
Dewey, J.W., 1976. 1976. Seismicity of Northern Anatolia, Bull. Seism. Soc. Am., 66, 843-868.

Bürgmann, R., Ergintav, S., Segall, P., Hearn, E.H., McClusky, S., Reilinger, R.E., Woith, H. and Zschau, J., 2002. Time-dependent distributed afterslip on and deep below the Izmit earthquake rupture. Bulletin of the Seismological Society of America, 92 (1), 126-137.

Cakir, Z., Ergintav, S., Akoğlu, A.M., Çakmak, R., Tatar, O. and Meghraoui, M., 2014. InSAR velocity field across the North Anatolian Fault (eastern Turkey): Implications for the loading and release of interseismic strain accumulation. Journal of Geophysical Research: Solid Earth, 119, 79347943, doi:10.1002/2014JB011360.

Cavalié, O., and Jónsson, S., 2014. Block-like plate movements in Eastern Anatolia observed by InSAR. Geophys. Res. Lett., 41, 26-31, doi:10.1002/2013GL058170.

Chorowicz J., Luxey P., Rudant J.-P., Lyberis N., Yürür T., Gündoğdu M.N., 1995, Slip-motion estimation along the Ovacık fault near Erzincan (Turkey) using ERS-1 Radar Image: evidence of important deformation inside the Turkish Plate. Remote Sensing Environment, 52 (1), 66-70.

Christopher, S., Takeuchi, C.S. and Fialko, Y., 2012. Dynamic models of interseismic deformation and stress transfer from plate motion to continental transform faults. Journal of Geophysical Research: Solid Earth, 117 (B05403), 1-16, doi:10.1029/2011JB009056.

Di Giacomo, D., Bondár, I., Storchak, D.A., Engdahl, E.R., Bormann, P. and Harris, J., 2015. ISCGEM: Global Instrumental Earthquake Catalogue (1900-2009): III. Re-computed MS and mb, proxy MW, final magnitude composition and completeness assessment, Phys. Earth Planet. Int., 239, 33-47, doi: 10.1016/j.pepi.2014.06.005.

Di Giacomo, D., Engdahl, E.R. and Storchak, D.A., 2018. The ISC-GEM Earthquake Catalogue (1904-2014): status after the Extension Project, Earth Syst. Sci. Data, 10, 1877-1899, doi: 10.5194/essd-10-1877.

Ergintav, S., McClusky, S., Hearn, E., Reilinger, R., Cakmak, R., Herring, T., Ozener, H., Lenk, O. and Tari, E., 2009. Seven years of postseismic deformation following the 1999, $M=7.4$ and $M=$ 7.2, Izmit-Düzce, Turkey earthquake sequence. Journal of Geophysical Research (Solid Earth), 114, B07403, 1-19, doi:10.1029/2008JB006021. 
Fuenzalida, H., Dorbath, L., Cisternas, A., Eyidoğan, H., Barka, A., Rivera, L., Haessler, H., Philip, H and Lyberis, N., 1997. Mechanism of the 1992 Erzincan earthquake and its aftershocks, tectonics of the Erzincan basin and decoupling on the North Anatolian fault.Geophys. Int. J., 129, 1-28, 1997.

Gencoğlu, S., İnan, E. and Güler, H., 1990.The earthquake hazard in Turkey, Publ. Cham.Geophys. Eng., Ankara, $701 \mathrm{p}$.

Goldstein, R.M., Engelhardt, H., Kamb, B. and Frolich, R.M., 1993. Satellite radar interferometry for monitoring ice sheet motion: Application to an Antarctic ice stream. Science, vol. 262, no. 23, pp. 1525-1530.

Hanssen, R.F., 2001. Radar Interferometry: Data Interpretation and Error Analysis. Kluwer Academic Publishers, Dordrecht.

Hearn, E., McClusky, S., Ergintav, S. and Reilinger, R., 2009. Izmit earthquake postseismic deformation and dynamics of the North Anatolian Fault Zone. Journal of Geophysical Research: Solid Earth, 114 (B08405), 1-21, doi:10.1029/2008JB006026.

Hearn, E.H., Bürgmann, R. and Reilinger, R.E., 2002. Dynamics of Izmit earthquake postseismic deformation and loading of the Duzce earthquake hypocenter. Bulletin of the Seismological Society of America, 92 (1), 172-193.

Hetland, E. and Hager, B., 2006. The effects of rheological layering on post-seismic deformation. Geophysical Journal International, 166 (1), 277-292.

Hussain, E., 2016. Mapping and modelling the spatial variation in strain accumulation along the North Anatolian Fault. Ph.D. thesis, University of Leeds, UK.

Hussain, E., Wright, T.J., Walters, R.J., Bekaert, D., Hooper, A. and Houseman, G.A., 2016 a. Geodetic observations of postseismic creep in the decade after the 1999 Izmit earthquake, Turkey: Implications for a shallow slip deficit. J. Geophys. Res. Solid Earth, 121, 2980-3001, doi:10.1002/2015JB012737.

Hussain, E., Hooper, A., Wright, T.J., Walters, R.J. and Bekaert, D.P., 2016b. Interseismic strain accumulation across the central North Anatolian Fault from iteratively unwrapped insar measurements. J. Geophys. Res. Solid Earth 121, 9000-9019 
Hussain, E., Wright, T.J., Walters, R.J., Bekaert, D.P.S., Lloyd, R. and Hooper, A., 2018. Constant strain accumulation rate between major earthquakes on the North Anatolian Fault. Nature Communications, 9, 1392 (2018) doi:10.1038/s41467-018-03739-2 .

Johnson, K.M., Hilley, G.E. and Bürgmann, R., 2007. Influence of lithosphere viscosity structure on estimates of fault slip rate in the Mojave region of the San Andreas fault system. Journal of Geophysical Research, 112 (B07408), 1-15.

Jolivet, R., Lasserre, C., Doin, M.-P., Guillaso, S., Peltzer, G., Dailu, R., Sun, J., Shen, Z.-K.and Xu, $X ., 2012$. Shallow creep on the Haiyuan Fault (Gansu, China) revealed by SAR Interferometry. J. Geophys. Res., 117, B06401, doi:10.1029/2011JB008732.

Kaneko, Y., Fialko, Y., Sandwell, D.T., Tong, X., and Furuya, M., 2013. Interseismic deformation and creep along the central section of the North Anatolian fault (Turkey): InSAR observations and implications for rate-and-state friction properties. J. Geophys. Res. Solid Earth, 118, 316-331, doi:10.1029/2012JB009661.

Kenner, S.J. and Segall, P., 2000. Postseismic deformation following the 1906 San Francisco earthquake. Journal of Geophysical Research: Solid Earth, 105 (B6), 13195-13209.

Koçyiğit, A. and Rojay, B., 1992a. Erzincan basin and 1992/3/13-15 earthquakes: an active composite pull-apart basin on the North Anatolian fault zone, Türkiye, Abstract presented in International Workshop: Work in progress on the geology of Türkiye, Keele, April 9-10, 1992. Univ. Keele, Dep. Geology.

Koçyiğit, A. and Rojay, B., 1992b. A preliminary neotectonic report on the Erzincan earthquake, 1992, 13 March, TUBITAK, Ankara.

Köse, O., 2000. Kuzey Anadolu Fay Kuşağı'nda tektonik gerilim birikim noktalarının uzaktan algılama teknikleri ile belirlenmesi. Hacettepe Üniv., Fen Bil. Enst., Ankara.

Lapusta, N. and Liu, Y., 2009. Three-dimensional boundary integral modeling of spontaneous earthquake sequences and aseismic slip. Journal of Geophysical Research: Solid Earth, 114 (B09303), 1-25, doi:10.1029/2008JB005934.

Marone, C., 1998. Laboratory-derived friction laws and their application to seismic faulting. Annual Review of Earth and Planetary Sciences, 26 (1), 643-696. 
Massonnet, D. and Feigl, K.L., 1995. Discrimination of geophysical phenomena in satellite radar interferograms, Geophysical Research Letters, 22 (12): 1537-1540.

Massonnet D. and Feigl K.L., 1998, Radar interferometry and its application to changes in the earth's surface. Reviews of Geophysics, 36, 4, 441-400.

Massonnet, D. and Rabaute, T., 1993. Radar interferometry: Limits and Potential. IEEE Transactions on Geoscience and Remote Sensing, vol. 31, no. 2, pp. 455-464.

Massonnet, D., Rossi, M., Carmona, C., Adragna, F., Peitzer, G., Feigl, K. and Rabaute, T., 1993.The displacement field of the Landers earthquake mapped by radar interferometry.Nature, vol. 364, No. 6433.

Meade, B.J., Klinger, Y., and Hetland, E.A., 2013. Inference of multiple earthquake cycle relaxation timescales from irregular geodetic sampling of interseismic deformation. Bulletin of the Seismological Society of America, 103 (5), 2824-2835.

Nalbant, S., Barka, A. and Alptekin, Ö., 1996. Failure stress change caused by the 1992 Erzincan Earthquake (Ms=6.8). Geophysical Research Letters, 23 (13), 1561-1564, doi:10.1029/96GL01323.

Peltzer, G., Rosen, P., Rogez, F. and Hudnut, K., 1996. Postseismic rebound in fault step-overs caused by pore fluid flow. Science, 273 (5279), 1202-1204, DOI: 10.1126/science.273.5279.1202.

Pinar, A., Honkura, Y. and Kikuchi, M., 1994. Rupture process of the 1992 Erzincan Earthquake and its implication for seismotectonics in eastern Turkey. Geophysical Research Letters, 21 (18), 1971-1974, doi:10.1029/94GL01712.

Pollitz, F.F., 2005. Transient rheology of the upper mantle beneath central Alaska inferred from the crustal velocity field following the 2002 Denali earthquake. Journal of Geophysical Research: Solid Earth, 110 (B08407), 1-16, doi:10.1029/2005JB003672.

Prescott, W.H. and Nur, A., 1981. The accommodation of relative motion at depth on the San Andreas Fault System in California. Journal of Geophysical Research: Solid Earth, 86 (B2), 999-1004.

Reilinger, R.E, McClusky, S.C., Oral, M.B., King, R.W., Toksöz, M.N., Barka, A.A., Kınık, I., Lenk, O. and Şanlı, I., 1997. Global Positioning System measurements of present-day crustal movements 
in the Arabia-Africa-Eurasia plate collision zone. Journal of Geophysical Research, vol. 102, No. B5:9983-9999.

Rossi, M., 1996. Giving an Operational Status to ERS Interferometric Applications. Proceedings of the Second ERS Applications Workshop, London, UK, 6-8 December 1995 (ESA SP-383 February 1996).

Savage, J.C. and Burford, R.O., 1973. Geodetic determination of relative plate motion in central California. Journal of Geophysical Research, 78, 832-845, doi:10.1029/JB078i005p00832.

Savage, J.C. and Prescott, W., 1978.Asthenosphere readjustment and the earthquake cycle. Journal of Geophysical Research: Solid Earth, 83 (B7), 3369-3376.

Savage, J.C, 2000. Viscoelastic-coupling model for the earthquake cycle driven from below. Journal of Geophysical Research, 105 (B11), 25525-25532.

Scholz, C.H., 1988. The critical slip distance for seismic faulting. Nature, 336, 761-763.

Sipahioğlu, Ş., 1983. An evaluation on characteristics of earthquake activity of the Horasan-Narman region before the 30 October 1983 earthquake (in Turkish). Yeryuvarı ve İnsan (Türkiye Jeoloji Kurumu), 8, 3. pp. 12-15.

Soysal, H., Sipahioğlu, Ş., Kolçak, D. and Altınok, Y., 1981. Catalogue of historical earthquakes of Turkey (in Turkish).TUBITAK Project No.TBAG 341, 86 pp.

Stchepinsky, V., Firat, H., Ulusan, C. and Pamir, H.N., 1940. Report on the observations in the Erzincan-Kelkit earthquake area (in Turkish). Unpublished MTA report, no. 1097, 23 pages, Ankara.

Tatar, O., Temiz, H., Tutkun, S.Z., Park, R.G. and Stimpson, I.G., 1993. Surface deformation and tectonic setting of the 13 March 1992 Erzincan earthquake, Eastern Turkey. Geol. J., 28: 327333. doi:10.1002/gj.3350280311.

Thatcher, W., 1983. Nonlinear strain buildup and the earthquake cycle. Journal of Geophysical Research, 88, 5893-5902. 
Tong, X., Sandwell, D.T., and Smith-Konter, B., 2013. High-resolution interseismic velocity data along the San Andreas Fault from GPS and InSAR, J. Geophys. Res. Solid Earth, 118, 369-389, doi:10.1029/2012JB009442.

Vaghri, A. and Hearn, E.H., 2012. Can lateral viscosity contrasts explain asymmetric interseismic deformation around strike-slip faults? Bulletin of the Seismological Society of America, 102 (2), 490-503.

Walters, R.J., Holley, R.J., Parsons, B. and Wright, T.J., 2011. Interseismic strain accumulation across the North Anatolian Fault from Envisat InSAR measurements, Geophys. Res. Lett., 38, L05303, doi:10.1029/2010GL046443.

Walters, R.J., Parsons, B. and Wright, T.J., 2014. Constraining crustal velocity fields with InSAR for Eastern Turkey: Limits to the block-like behaviour of Eastern Anatolia. Journal of Geophysical Research: Solid Earth, 119, 5215-5234, doi:10.1002/2013JB010909.

Wang, H., and Wright, T.J., 2012. Satellite geodetic imaging reveals internal deformation of western Tibet. Geophys. Res. Lett., 39, L07303, doi:10.1029/2012GL051222.

Wright, T.J., Parsons, B. and Fielding, E., 2001. Measurement of interseismic strain accumulation across the North Anatolian Fault by satellite radar interferometry, Geophys. Res. Lett., 28, $2117-$ 2120, doi:10.1029/2000GL012850.

Wright, T., 2016. The earthquake deformation cycle. AG: News \& Reviews in Astronomy \& Geophysics, 57, (4), 20-27

Yamasaki, T. and Houseman, G.A., 2012.The signature of depth-dependent viscosity structure in post-seismic deformation. Geophysical Journal International, 190 (2), 769-784.

Zebker, H.A. and Goldstein, R.M., 1986. Topographic mapping from interferometric SAR observations. Journal of Geophysical Research, vol. 91, no. B5, pp. 4993-4999. 